\title{
Differences in urinary incontinence symptoms and pelvic floor structure changes during pregnancy between nulliparous and multiparous women
}

\author{
Dan Luo ${ }^{1}$, Ling Chen ${ }^{1}$, Xiajuan Yu ${ }^{1,2}$, Li Ma ${ }^{3}$, Wan Chen ${ }^{3}$, Ning Zhou ${ }^{3}$, Wenzhi Cai ${ }^{\text {Corresp. }}{ }^{1}$ \\ 1 Department of Nursing, Shenzhen hospital of Southern Medical University, Shenzhen, Guangdong, China \\ 3 Department of Ultrasound, Shenzhen Hospital of Southern Medical University, Shenzhen, Guangdong, China \\ Corresponding Author: Wenzhi Cai \\ Email address: kfzywyh@126.com
}

Background. This study was performed to compare changes in urinary incontinence (UI) symptoms and pelvic floor structure during pregnancy between nulliparous and multiparous women.

Methods. A cross-sectional survey was performed among pregnant women from July 2016 to January 2017. In total, 358 pregnant women from 2 hospitals underwent an interview and pelvic floor transperineal ultrasound assessment. A questionnaire regarding sociodemographic, gynecological, obstetric features and the International Consultation on Incontinence Questionnaire-Short Form (ICIQ-SF) were used for the interview. Imaging data sets were analyzed offline to assess the bladder neck vertical position (BNVP), urethral angles ( $\alpha, \beta$, and $\gamma$ angles), and hiatal area (HA) at rest and at maximal Valsalva maneuver (VM).

Results. After excluding 16 women with invalid data, 342 women were included. The prevalence $\left(X^{2}=9.15, P=0.002\right)$, frequency $(t=2.52, P=0.014)$, usual amount of $U I(t=2.23, P=0.029)$ and scores of interference with daily life $(t=2.03, P=0.045)$ during pregnancy were higher in multiparous than nulliparous women. A larger bladder neck descent (BND) $(F=4.398, P<0.001), \mathrm{HA}(F=6.977, P<0.001), \alpha$ angle $(F=2.178, P=0.030), \beta$ angle $(F=4.404, P<0.001)$, and $\gamma$ angle $(F=2.54, P=0.011)$ at VM were discovered in pregnant women with UI than without UI. Multiparous women had a significantly higher $\operatorname{BND}(t=2.269, P=0.024)$ and a larger $\alpha$ angle $(F=2.894, P=0.004), \beta$ angle $(F=2.473, P=0.014)$, and $Y$ angle $(F=3.255, P=0.001)$ at VM than did nulliparous women.

Conclusion. Multiparous women experienced more obvious UI symptoms and pelvic floor structure changes during pregnancy than did nulliparous women. 
1 Differences in urinary incontinence symptoms and pelvic floor structure changes during pregnancy between nulliparous and multiparous women

3 Dan $\mathrm{Luo}^{1 *}$, Ling Chen ${ }^{1 *}$, Xiajuan $\mathrm{Yu}^{1,2}, \mathrm{Li} \mathrm{Ma}^{3}$, Wan Chen ${ }^{3}$, Ning Zhou ${ }^{3}$ and Wenzhi Cai ${ }^{1}$

$4 \quad{ }^{1}$ Department of Nursing, Shenzhen hospital of Southern Medical University, Shenzhen,

5 Guangdong, China.

$6{ }^{2}$ Department of Neonatology, Shenzhen Maternity \& Child Health Care Hospital, Shenzhen,

7 Guangdong, China.

$8{ }^{3}$ Department of Ultrasound, Shenzhen Hospital of Southern Medical University, Shenzhen,

9 Guangdong, China.

10 Corresponding Author:

11 Wenzhi Cai ${ }^{1}$

121333 Xinhu Road, Baoán District, Shenzhen, Guangdong, 518101, China.

13 Email address: kfzywyh@126.com.

$14 *$ These authors contributed equally to this work. 
15

16

17

ABSTRACT

Background. This study was performed to compare changes in urinary incontinence (UI) symptoms and pelvic floor structure during pregnancy between nulliparous and multiparous women.

Methods. A cross-sectional survey was performed among pregnant women from July 2016 to January 2017. In total, 358 pregnant women from 2 hospitals underwent an interview and pelvic floor transperineal ultrasound assessment. A questionnaire regarding sociodemographic, gynecological, obstetric features and the International Consultation on Incontinence Questionnaire-Short Form (ICIQ-SF) were used for the interview. Imaging data sets were analyzed offline to assess the bladder neck vertical position (BNVP), urethral angles ( $\alpha, \beta$, and $\gamma$ angles), and hiatal area (HA) at rest and at maximal Valsalva maneuver (VM).

Results. After excluding 16 women with invalid data, 342 women were included. The prevalence $\left(\chi^{2}=9.15, P=0.002\right)$, frequency $(t=2.52, P=0.014)$, usual amount of UI $(t=2.23$, $P=0.029)$ and scores of interference with daily life $(t=2.03, P=0.045)$ during pregnancy were higher in multiparous than nulliparous women. A larger bladder neck descent (BND) $(F=4.398$, $P<0.001)$, HA $(F=6.977, P<0.001), \alpha$ angle $(F=2.178, P=0.030), \beta$ angle $(F=4.404, P<0.001)$, and $\gamma$ angle $(F=2.54, P=0.011)$ at $\mathrm{VM}$ were discovered in pregnant women with UI than without UI. Multiparous women had a significantly higher $\operatorname{BND}(F=2.269, P=0.024)$ and a larger $\alpha$ angle $(F=2.894, P=0.004), \beta$ angle $(F=2.473, P=0.014)$, and $\gamma$ angle $(F=3.255, P=0.001)$ at $\mathrm{VM}$ than did nulliparous women.

Conclusion. Multiparous women experienced more obvious UI symptoms and pelvic floor structure changes during pregnancy than did nulliparous women.

\section{INTRODUCTION}

In 2002, the International Continence Society (ICS) defined urinary incontinence (UI) as "the involuntary passage of urine for any reason" (Abrams et al., 2002). UI is a common condition during pregnancy, with a prevalence of $16.8 \%$ to $72.0 \%$ (Adaji et al., 2011; Bo et al., 2012; Tanawattanacharoen \& Thongtawee, 2013; Rincon, 2015; Abdullah et al., 2016). UI may exert a 
42 negative effect on pregnant women's working routines, free time activities, and sexual intimacy

43 (Wijma et al., 2001). Dolan et al. (Dolan et al., 2003) found that the risk of UI doubled 15 years

44 after the development of UI during a woman's first pregnancy.

45 However, studies of UI during pregnancy have mainly focused on nulliparous women; a limited number of epidemiological studies have targeted multiparous women (Hvidman et al., 2002; Raza-Khan et al., 2006; Scarpa et al., 2006; Wesnes et al., 2007; Al-Mehaisen et al., 2009). In a systematic review of the epidemiology of UI during pregnancy, the estimated incidence of $\mathrm{UI}$ in pregnancy ranged from $45 \%$ to $54 \%$ among multiparous women but only $28 \%$ to $45 \%$ among nulliparous women (Wesnes, Hunskaar \& Rortveit, 2012). Since implementation of the "Two-Child Policy" in China, the number of multiparous women is expected to increase. Thus, UI during pregnancy in multiparous women should be taken seriously.

The pathophysiology of UI during pregnancy involves pregnancy-associated pelvic floor changes (Clement et al., 2013). Previous studies using transperineal ultrasound to assess changes in the pelvic floor anatomy during pregnancy in nulliparous women revealed that the predominant changes involved the levator hiatal dimensions and the position and mobility of the bladder neck (BN) (Dietz, 2004; Shek, Kruger \& Dietz, 2012; van Veelen, Schweitzer \& van der Vaart, 2014a; Chan et al., 2014). Although it is believed that multiparous women have a higher prevalence of UI than nulliparous women, the differences in the severity of UI and the changes in the pelvic floor structure during pregnancy between nulliparous and multiparous women remain unclear. Therefore, the aim of this study was to assess and compare the differences in the symptomatology of UI during pregnancy and the morphology of the pelvic floor anatomy between nulliparous and multiparous women to provide a scientific basis for further research in prenatal care.

\section{MATERIALS AND METHODS}

\section{Ethics statement}

Ethics approval for the study was granted by the Ethics Committee of Shenzhen Materity \& Child Health Care Hospital (2016-30). All participants provided written informed consent. 
69

70

\section{Participants}

Three hundred fifty-eight women with a singleton pregnancy who were undergoing routine antenatal assessment in the obstetric clinics of various hospitals of Shenzhen from July 2016 to January 2017 were recruited. The exclusion criteria were 1) a history of UI before pregnancy; 2) a history of abdominal and vaginal surgery; 3) diabetes and hypertension; and 4) placenta previa, threatened abortion, amniotic fluid abnormalities, fetal growth restriction, or vaginal bleeding. The elimination criteria were 1) a failure to complete all investigation content and 2) unreliable pelvic ultrasound data.

An interview of the patients was conducted by XJ Y to investigate the patients' age, gestational weeks, body mass index (BMI), constipation during pregnancy, number of pregnancies, prior abortions/miscarriages, and delivery history. UI was diagnosed using the International Consultation of Incontinence Questionnaire-Short Form (ICIQ-SF). This questionnaire can also be used to evaluate the severity of UI. It comprises three scored items (Questions 1-3), frequency of UI (score range, 0-5), usual amount of UI (score range, 0-6), interference with everyday life (score range, 0-10), and a self-diagnostic item (Question 4, not scored) (Avery et al., 2004). This instrument is recommended by the ICS and has been validated in China (Huang et al., 2008).

\section{Transperineal ultrasound assessment}

After completing the interview covering the patients' general information and symptoms of UI, transperineal ultrasound examination was performed using a Voluson E8 system (GE Healthcare, Chicago, IL) with a 5-9 MHz three-dimensional autosweep transducer. The pregnant women should empty urine before examination and then lay in the supine position. The probe was smeared with a coupling agent and then covered with a condom. A vaginal probe was placed between the two labia, directly below the urethral orifice. The symphysis pubis was set as the axis point indication, and the median sagittal plane of the vagina, urethra, and anal canal was then obtained. Volume scanning was performed, the selection box was properly adjusted, and the $\mathrm{BN}$, urethra, vagina, proximal anal canal, distal anal canal, and pubic symphysis were scanned. 
96

97

Two- and three-dimensional cross-sectional sonograms of the pelvic floor in the resting position and at maximal Valsalva maneuver (VM) were collected. The VM process lasted for approximately $5 \mathrm{~s}$ until satisfactory images were obtained. Ultrasound assessment was performed by three experienced investigators (LM, NZ, and WC) who were blinded to all other information. During the examination, the probe remained closely attached to the perineum to prevent air interference and ensure that the quality of the picture was not affected.

Offline analysis of the imaging data sets was conducted using the GE Kretz 4D View version 10.3 software program (GE Healthcare). All data sets were analyzed by one of two investigators (DL or LC) who were blinded to the UI symptoms. The reference line was a horizontal line placed at the inferoposterior margin of the symphysis pubis. The following parameters were measured at rest and VM: 1) bladder neck vertical position (BNVP): distance (in $\mathrm{cm}$ ) between the $\mathrm{BN}$ and the inferior-posterior margin of the symphysis pubis. A positive value indicated that the $\mathrm{BN}$ was positioned cranial of the symphysis pubis and a negative value that is was positioned caudal of the symphysis pubis. Bladder neck descent (BND) is the difference of BN between VM and rest (Dietz, 2011); 2) $\alpha$ angle: the angle between the proximal urethra and the trigone (Volloyhaug et al., 2016); 3) $\beta$ angle: the angle between the bladder necksymphysis line and the middle of the symphysis (Pregazzi et al., 2002); 4) $\gamma$ angle: the angle between the proximal urethra and the horizontal line (Volloyhaug et al., 2016); 5) hiatal area (HA) was measured as the area $\left(\right.$ in $\mathrm{cm}^{2}$ ) bordered by the pubovisceral muscle, pubic symphysis and the inferior pubic ramus (van Veelen, Schweitzer \& van der Vaart, 2014a), (Fig. 1).

\section{Statistical analysis}

SPSS 13.0 (SPSS Inc., Chicago, IL) and GraphPad Prism 5.0 (GraphPad, San Diego, CA) were used for all statistical analyses. Descriptive statistics were presented as mean \pm standard deviation for continuous variables and as frequency (percentage) for categorical variables. Student's $t$ test was used to analyze quantitative data. Chi-square test was used for categorical data. Covariance analyses (gestational weeks as the covariate) were conducted to compare the ultrasound parameters between pregnant women with and without UI and between nulliparous 
123 and multiparous women. All statistical tests were two-tailed. The level of significance was set at 1240.05.

\section{RESULTS}

126 Comparisons of demographic characteristics between nulliparous and multiparous women

127 Ten pregnant women failed to perform the VM effectively (generally, HA should be larger at

128 VM than at rest; the data were considered invalid if the HA results were exactly the opposite),

129 and six did not finish the interview. Therefore, 342 pregnant women were included in our final

130 data analysis. Among those who completed the study, 179 were nulliparous women and 163

131 were multiparous women. Table 1 shows the demographic characteristics of the study population

132 and the associated factors between the nulliparous and multiparous groups. There were

133 significant differences in age, number of pregnancies, and prior miscarriages/abortions between

134 the nulliparous and multiparous women (Table 1).

135

136

137

138

139

140

141

142

143

144

145

146

147

148

149

\section{Comparison of UI severity during pregnancy between nulliparous and multiparous women}

The results of the comparison of the prevalence and severity of UI between the nulliparous and multiparous women are shown in Fig. 2. Fifty-seven (31.8\%) nulliparous women and 78 (47.9\%) multiparous women were diagnosed with UI during pregnancy. The prevalence of UI was significantly different between these two groups $\left(\chi^{2}=9.15, P=0.002\right)$. The scores for the frequency of UI ((1.55 \pm 0.56$)$ vs. (1.21 \pm 0.63$))$, usual amount of UI( (2.53 \pm 0.85$)$ vs. $(2.14 \pm 0.52))$, and interference with daily life $((3.58 \pm 1.86)$ vs. $(2.67 \pm 2.09))$ were significantly higher in multiparous than nulliparous women (all $P<0.05)$.

\section{Comparison of pelvic floor ultrasound parameters between pregnant women with and}

\section{without UI}

The results of the covariance analysis of pelvic floor ultrasound parameters (gestational weeks as the covariate) are shown in Table 2. Pregnant women with UI showed a larger $\beta$ angle and HA than those without UI at rest. The $\alpha$ angle, $\beta$ angle, $\gamma$ angle, BNVP and HA at VM were significantly different between pregnant women with and without UI. Larger differences in $\beta$ angle, BNVP, and HA between VM and rest were found in pregnant women with UI than 
150

151

152

153

154

155

156

157

158

159

160

161

162

163

164

165

166

167

168

169

170

171

172

173

174

175

176

without UI. The $\alpha$ angle and $\gamma$ angle at rest and between VM and rest as well as the BNVP at rest were not significantly different between the two groups (Table 2).

\section{Comparison of pelvic floor ultrasound parameters during pregnancy between nulliparous} and multiparous women

Table 3 shows the covariance analysis results of pelvic floor ultrasound parameters (gestational weeks as the covariate) between nulliparous and multiparous women. The $\alpha$ angle, $\beta$ angle, $\gamma$ angle, and BNVP during pregnancy were significantly different at VM between nulliparous and multiparous women. Multiparous women showed a larger $\alpha$ angle and $\gamma$ angle between VM and rest than did nulliparous women. The BND was significantly different between nulliparous and multiparous women. However, the HA was not significantly different between nulliparous and multiparous women.

\section{DISCUSSION}

Multiparous women experienced more severe symptoms of UI than did nulliparous women. The rate of UI in nulliparous women was $31.8 \%$, which was significantly lower than that in multiparous women (47.9\%). Our results are basically consistent with those of previous studies (Wesnes et al., 2007; Lin et al., 2014). UI, described as "social cancer", has been listed as one of the five most common chronic diseases worldwide according to the World Health Organization and remains a global problem affecting women of all ages and across different cultures and races (Minassian, Drutz\&Al-Badr, 2003). In the present study, we discovered a higher frequency of UI, the larger usual amount of UI, and more serious interference with daily life in multiparous than nulliparous women. With the implementation of the "Two-Child Policy" in China, the growing number of multiparous women has drawn attention to the screening and prevention of UI during pregnancy.

Most previous studies of the relationship between UI during pregnancy and pelvic structure merely took nulliparous women into consideration. In addition to the higher prevalence of UI and more severe UI symptoms among multiparous than nulliparous women, our study also revealed that multiparous women experienced more obvious changes in their pelvic structure 
177 than did nulliparous women. Urethral support plays a critical role in the pathogenesis of UI. The 178 BN position, BN mobility, and HA can be regarded as objective indicators of the supportive 179 capacity of the pelvic floor, which can be measured effectively by transperineal ultrasound 180 (Dietz, 2004; Majida et al., 2009; Shek \& Dietz, 2010; Siafarikas et al., 2013; Jundt et al., 2010).

181

182

183

184

185

186

187

The $\alpha$ angle, $\beta$ angle, $\gamma$ angle, and BNVP indicate the BN position. Differences in these parameters between VM and rest represent BN mobility; larger differences indicate more obvious BN activity and weaker pelvic floor support. Levator ani muscle trauma may lead to a larger width of the HA, particularly its anterior part (Svabik, Shek \& Dietz, 2009), which has been found to be associated with the development of UI (Chan et al., 2016). A larger $\beta$ angle and HA both at rest and VM; a larger $\alpha$ angle, $\gamma$ angle, and BNVP at VM; and a larger BND have also been found in pregnant women with UI than without UI, even after adjustment for the influence of gestational weeks, which is important because UI symptoms are more likely to occur in the last than first trimester of pregnancy (Wesnes, Hunskaar \& Rortveit, 2012). All of these pelvic floor parameters ( $\alpha$ angle, $\beta$ angle, $\gamma$ angle, HA, and BNVP) have shown good intraclass correlation coefficients in previous studies (Pregazzi et al., 2002; Chan et al., 2014; Naranjo-Ortiz et al., 2016). Our results are similar to those of previous studies. Chan et al. (Chan et al., 2014) found that a greater BND increased a woman's likelihood of developing UI during pregnancy. Al-Saadi (Al-Saadi, 2016) found that women with UI had a larger $\alpha$ angle and $\beta$ angle at VM than did women without UI. Sendag et al. (Sendag et al., 2003) reported that women with UI had a larger $\alpha$ angle and $\gamma$ angle at VM than did women without UI. A study by Veelen et al. (van Veelen, Schweitzer \& van der Vaart, 2014b) showed significant differences in the HA at rest and at VM between pregnant women with and without UI. We found that the BND, HA, $\beta$ angle, and $\gamma$ angle at VM were greater in women with UI than without UI, confirming the results of previous studies.

Multiparous women experienced more obvious pelvic changes than did nulliparous women in the present study. Multiparous women had larger $\alpha, \beta$, and $\gamma$ angles and a larger BNVP at VM as well as a larger BND than did nulliparous women during pregnancy after adjustment for the 
204 influence of gestational weeks. As mentioned above, the $\alpha$ angle, $\beta$ angle, $\gamma$ angle, and BNVP at

205

206

207

208

209

210

211

212

213

214

215

216

217

218

219

220

221

222

223

224

225

226

227

228

229

230

VM and the BND have been found to differ between pregnant women with and without UI; thus, we were not surprised to find that multiparous women experienced more significant pelvic floor changes than nulliparous women during pregnancy.

Multiparous women also showed higher age, larger numbers of pregnancies, and a higher prevalence of prior miscarriages/abortions than did nulliparous women in our study, which might explain why multiparous women were more susceptible to UI and pelvic floor changes than nulliparous women. The previous studies reported that higher age leads to the loss of nerve function and a decrease in the total number of striated muscle fibers of the urethral sphincter at a rate of $2 \%$ per year and a gradual decline in the maximum urethral closure pressure of approximately 15\% per decade (Pandit et al., 2000; Wesnes \& Lose, 2013). A previous study demonstrated that pregnancy itself has an effect on the pelvic floor (Dietz et al., 2004); the mechanical and hormonal effects of pregnancy can lead to biomechanical, neurological, or neuromuscular changes to the pelvic floor and pelvic organ support (South MM et al., 2009; Chen B et al., 2005), which may lead to more obvious BN mobility and contribute to pelvic floor dysfunction. Brown et al. (Brown et al., 2010) investigated 1507 pregnant women and found that prior miscarriages/abortions was a significantly high risk factor for UI during pregnancy; our results are consistent with these findings. However, our data require a further cohort study to verify the reasons why multiparous women developed more severe UI symptoms and pelvic floor structure changes during pregnancy than did nulliparous women.

\section{LIMITATIONS}

One of the limitations of our study is its cross-sectional design. To elucidate the pathophysiology of delivery-induced UI, women should ideally be examined before, during, and after their pregnancy to assess preexisting differences in the pelvic floor anatomy and the absence of UI before, during, and after pregnancy (Chan et al., 2014). Additionally, we could not eliminate the possibility that some patients were unable to push downward to the extent required for the VM, which may have resulted in underestimation of the actual pelvic floor parameters. 


\section{CONCLUSIONS}

232 Our results indicate that multiparous women had a higher prevalence of UI and more severe UI 233 symptoms than did nulliparous women, which could be associated with weaker pelvic floor 234 support.

235

236

237

238

239

\section{REFERENCES}

Abdullah B, Ayub SH, Mohd ZA, Noorneza AR, IsaMR, Ng PY. 2016. Urinary incontinence in primigravida: the neglected pregnancy predicament. European Journal of Obstetrics \& Gynecology and Reproductive Biology 198:110-115 DOI 10.1016/j.ejogrb.2016.01.006.

Abrams P, Cardozo L, Fall M, Griffiths D, Rosier P, Ulmsten U, van Kerrebroeck P, Victor A, Wein, A. 2002. The standardisation of terminology of lower urinary tract function: report from the Standardisation Sub-committee of the International Continence Society. Neurourology \& Urodynamics 21:167-178 DOI 10.1016/S0090-4295(02)02243-4.

Adaji SE, Shittu OS, Bature SB, Nasir S, Olatunji O. 2011. Bothersome lower urinary symptoms during pregnancy: a preliminary study using the International Consultation on Incontinence Questionnaire. African Health Sciences 11 Suppl 1:S46-S52.

Al-Mehaisen LM, Al-Kuran O, Lataifeh IM, Betawie S, Sindiyani A, Al-ttal OF, Naser F2009. Prevalence and frequency of severity of urinary incontinence symptoms in late pregnancy: a prospective study in the north of Jordan. Archives of Gynecology \& Obstetrics 279:499-503 DOI 10.1007/s00404-008-0720-6.

Al-Saadi WI. 2016. Transperineal ultrasonography in stress urinary incontinence: The significance of urethral rotation angles. Arab Journal of Urology 14:66-71 DOI 10.1016/j.aju.2015.11.003.

Avery K, Donovan J, Peters TJ, Shaw C, Gotoh M, Abrams P. 2004. ICIQ: a brief and robust measure for evaluating the symptoms and impact of urinary incontinence. Neurourology \& Urodynamics 23:322-330 DOI 10.1002/nau.20041.

Bo K, Pauck OG, SletnerL, Morkrid K, and Jenum AK. 2012. The prevalence of urinary incontinence in pregnancy among a multi-ethnic population resident in Norway. BJOG An 
258

259

260

261

262

263

264

265

266

267

268

269

270

271

272

273

274

275

276

277

278

279

280

281

282

283

284

International Journal of Obstetrics \& Gynaecology119:1354-1360 DOI 10.1111/j.14710528.2012.03435.x.

Brown SJ, Donath S, MacArthur C, McDonald EA, Krastev AH. 2010. Urinary incontinence in nulliparous women before and during pregnancy: prevalence, incidence, and associated risk factors. International Urogynecology Journal 21:193-202 DOI 10.1007/s00192-009-1011-x.

Chan SS, Cheung RY, Lee LL, Choy KW, Chung TK. 2017. A longitudinal follow-up of levator ani muscle avulsion: does a second delivery affect it? Ultrasound in Obstetrics \& Gynecology the Official Journal of the International Society of the Ultrasound in Obstetrics \& Gynecology DOI 10.1002/uog.16009.

Chan SS, Cheung RY, Yiu KW, Lee LL, Leung, TY, Chung TK. 2014. Pelvic floor biometry during a first singleton pregnancy and the relationship with symptoms of pelvic floor disorders: a prospective observational study. BJOG An International Journal of Obstetrics \& Gynaecology 121:121-129 DOI 10.1111/1471-0528.12400.

Chen B, Wen Y, Yu X, Polan M L. 2005. Elastin metabolism in pelvic tissues: is it modulated by reproductive hormones? American Journal of Obstetrics \& Gynecology 192(5):1605. DOI 10.1016/j.ajog.2004.11.027.

Clement KD, Lapitan MC, Omar MI, Glazener CM. 2013. Urodynamic studies for management of urinary incontinence in children and adults. The Cochrane Library Cochrane Database Systematic Reviewer 29(10): 203-203 DOI 10.1002/14651858.CD003195.pub3.

Dietz HP. 2004. Levator function before and after childbirth. Australian \& New Zealand Journal of Obstetrics and Gynaecology 44:19-23 DOI 10.1111/j.1479-828X.2004.00140.x.

Dietz HP. 2011. Pelvic floor ultrasound in incontinence: what's in it for the surgeon? International Urogynecology Journal 22:1085-1097 DOI 10.1007/s00192-011-1402-7.

Dietz HP, Eldridge A, Grace M, Clarke B. 2004. Does pregnancy affect pelvic organ mobility? Australian \& New Zealand Journal of Obstetrics \& Gynaecology 44:517-520 DOI 10.1111/j.1479-828X.2004.00301.x.

Dolan LM, Hosker GL, Mallett VT, Allen RE, Smith AR. 2003. Stress incontinence and pelvic 
285

286

287

288

289

290

291

292

293

294

295

296

297

298

299

300

301

302

303

304

305

306

307

308

309

310

311

floor neurophysiology 15 years after the first delivery. BJOG An International Journal of Obstetrics \& Gynaecology110:1107-1114 DOI 10.1111/j.1471-0528.2003.02415.x.

Huang L, Zhang SW, Wu SL, Ma L, Deng XH. 2008. The Chinese version of ICIQ: a useful tool in clinical practice and research on urinary incontinence. Neurourology \& Urodynamics 27:522-524 DOI 10.1002/nau.20546.

Hvidman L, Hvidman L, Foldspang A, Mommsen S, Bugge NJ. 2002. Correlates of urinary incontinence in pregnancy. Journal and Pelvic Floor Dysfunction 13:278-283 DOI $10.1007 / \mathrm{s} 001920200061$.

Jundt K, Scheer I, Schiessl B, Karl K, Friese K, Peschers UM. 2010. Incontinence, bladder neck mobility, and sphincter ruptures in primiparous women. European Journal of Medical Research 15:246-252 DOI 10.1186/2047-783X-15-6-246.

Lin KL, Shen CJ, Wu MP, Long CY, Wu CH, Wang CL. 2014. Comparison of low urinary tract symptoms during pregnancy between primiparous and multiparous women. Biomed Research International 2014:303697 DOI 10.1155/2014/303697.

Majida M, Braekken IH, Umek W, Bo K, Saltyte BJ, Ellstrom EM. 2009. Interobserver repeatability of three- and four-dimensional transperineal ultrasound assessment of pelvic floor muscle anatomy and function. Ultrasound in Obstetrics \& Gynecology 33:567-573 DOI 10.1002/uog.6351.

Minassian VA, Drutz HP, Al-Badr, A. 2003. Urinary incontinence as a worldwide problem. International Journal of Gynaecology and Obstetrics 82:327-338 DOI 10.1016/S00207292(03)00220-0.

Naranjo-Ortiz C, Shek KL, Martin AJ, Dietz HP. 2016. What is normal bladder neck anatomy? International Urogynecology Journal 27:945-950DOI 10.1007/s00192-015-2916-1.

Pandit M, DeLancey JO, Ashton-Miller JA, Iyengar J, Blaivas M, Perucchini D. 2000. Quantification of intramuscular nerves within the female striated urogenital sphincter muscle. Obstetrics and Gynecology 95:797-800 DOI org/10.1016/S0029-7844(00)00825-5.

Pregazzi R, Sartore A, Bortoli P, Grimaldi E, Troiano L, Guaschino S. 2002. Perineal ultrasound 
312

313

314

315

316

317

318

319

320

321

322

323

324

325

326

327

328

329

330

331

332

333

334

335

336

337

338

evaluation of urethral angle and bladder neck mobility in women with stress urinary incontinence. BJOG An International Journal of Obstetrics \& Gynaecology 109:821-827 DOI 10.1111/j.1471-0528.2002.01163.x.

Raza-Khan F, Graziano S, Kenton K, Shott S, Brubaker L. 2006. Peripartum urinary incontinence in a racially diverse obstetrical population. Journal and Pelvic Floor Dysfunction 17:525-530 DOI 10.1007/s00192-005-0061-y.

Rincon AO. 2015. Prevalence and risk factors for urinary incontinence among women consulting in primary care. Revista Medica De Chile 143:203-212 DOI 10.4067/S003498872015000200008 .

Scarpa KP, Herrmann V, Palma PC, Riccetto CL, Morais SS. 2006. Prevalence and correlates of stress urinary incontinence during pregnancy: a survey at UNICAMP Medical School, Sao Paulo, Brazil. Journal and Pelvic Floor Dysfunction 17:219-223 DOI 10.1007/s00192-005$1361-\mathrm{y}$.

Sendag F, Vidinli H, Kazandi M, Itil IM, Askar N, Vidinli B, Pourbagher A. 2003. Role of perineal sonography in the evaluation of patients with stress urinary incontinence. Australian \& New Zealand Journal of Obstetrics \& Gynaecology 43:54-57 DOI 10.1046/j.0004-8666.2003.00012.x.

Shek KL, Kruger J, Dietz HP. 2012. The effect of pregnancy on hiatal dimensions and urethral mobility: an observational study. International Urogynecology Journal 23:1561-1567 DOI 10.1007/s00192-012-1795-y.

Shek KL, Dietz HP. 2010. Intrapartum risk factors for levator trauma. BJOG An International Journal of Obstetrics \& Gynaecology 117:1485-1492 DOI 10.1111/j.14710528.2010.02704.x.

Siafarikas F, Staer-Jensen J, Braekken IH, Bo K, Engh ME. 2013. Learning process for performing and analyzing 3D/4D transperineal ultrasound imaging and interobserver reliability study. Ultrasound in Obstetrics \& Gynecology 41:312-317 DOI 10.1002/uog.11192. 
339 South MM, Stinnett SS, Sanders DB, Weidner AC. 2009. Levator ani denervation and 340 reinnervation 6 months after childbirth. American Journal of Obstetrics \& Gynecology, 341 200(5):1-7 DOI 10.1016/j.ajog.2008.12.044.

342 Svabik K, Shek KL, Dietz HP. 2009. How much does the levator hiatus have to stretch during 343 childbirth? BJOG An International Journal of Obstetrics and Gynaecology 116:1657-1662 DOI 10.1111/j.1471-0528.2009.02321.x.

345

Tanawattanacharoen S, Thongtawee S. 2013. Prevalence of urinary incontinence during the late third trimester and three months postpartum period in King Chulalongkorn Memorial Hospital. Journal of the Medical Association of Thailand 96:144-149.

van Veelen GA, Schweitzer KJ, van der Vaart CH. 2014a. Ultrasound imaging of the pelvic floor: changes in anatomy during and after first pregnancy. Ultrasound in Obstetrics and Gynecology 44:476-480 DOI 10.1002/uog.13301.

van Veelen GA, Schweitzer KJ, van der Vaart CH. 2014b. Ultrasound assessment of urethral support in women with stress urinary incontinence during and after first pregnancy. Obstetrics and Gynecology 124:249-256 DOI 10.1097/AOG.0000000000000355.

Volloyhaug I, van Gruting I, van Delft K, Sultan AH, Thakar R. 2016. Is bladder neck and urethral mobility associated with urinary incontinence and mode of delivery 4 years after childbirth? Neurourology \& Urodynamics DOI 10.1002/nau.23123.

Wesnes SL, Rortveit G, Bo K, Hunskaar S. 2007. Urinary incontinence during pregnancy. Obstetrics and Gynecology 109:922-928 DOI 10.1097/01.AOG.0000257120.23260.00.

Wesnes SL, Hunskaar S, Rortveit G. 2012. Epidemiology of Urinary Incontinence in Pregnancy and Postpartum. Urinary incontinence. Croatia: In Tetch, 21-39.

Wesnes SL, Lose G. 2013. Preventing urinary incontinence during pregnancy and postpartum: a review. International Urogynecology Journal 24:889-899 DOI 10.1007/s00192-012-2017-3.

Wijma J, Weis PA, de Wolf BT, Tinga DJ, and Aarnoudse JG. 2001. Anatomical and functional changes in the lower urinary tract during pregnancy. BJOG An International Journal of Obstetrics \& Gynaecology 108:726-732 DOI 10.1111/j.1471-0528.2001.00123.x. 


\section{Figure 1}

Transperineal ultrasound measurement of pregnant women.

$B=$ bladder; $S=$ symphysis pubis; $U=$ urethra; $V=$ vagina; $A=$ anus; $B N V P=$ bladder neck vertical position; $\mathrm{HA}=$ hiatal area.
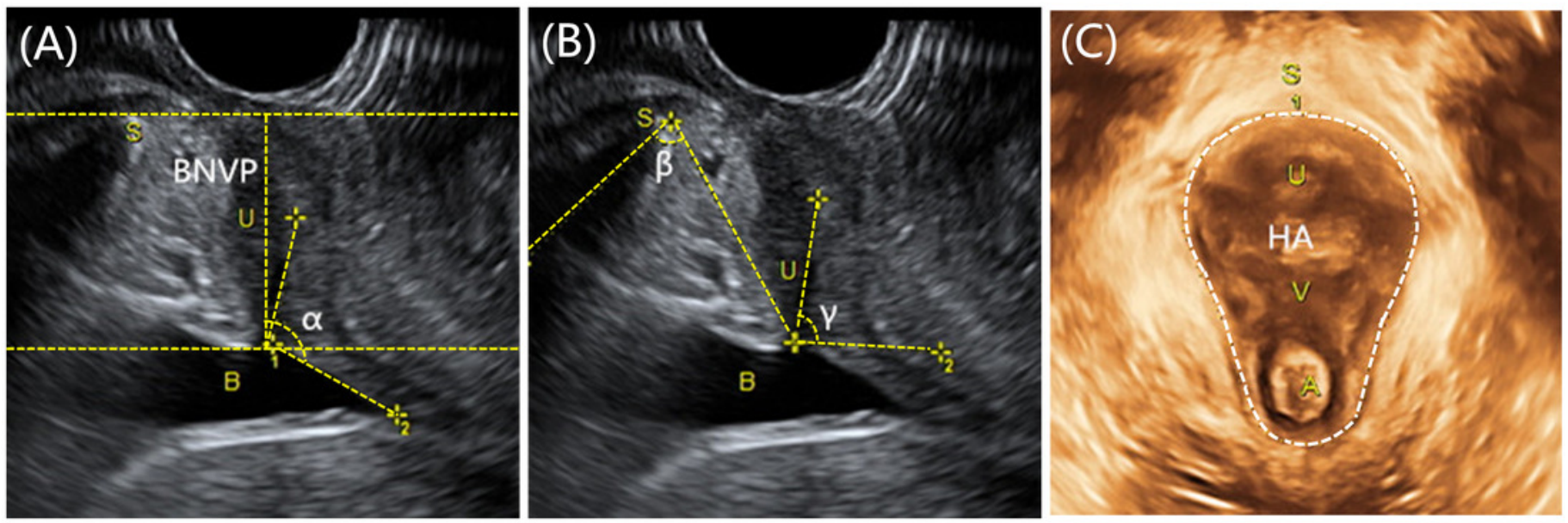
Figure 2

Comparison of prevalence and severity of UI between nulliparous and multiparous women.

(A) comparison of prevalence rate of $\mathrm{UI}$; (B) comparison of frequency of $\mathrm{UI}$; (C) comparison of usual amount of UI; (D) comparison of interference with daily life. UI=urinary incontinence.

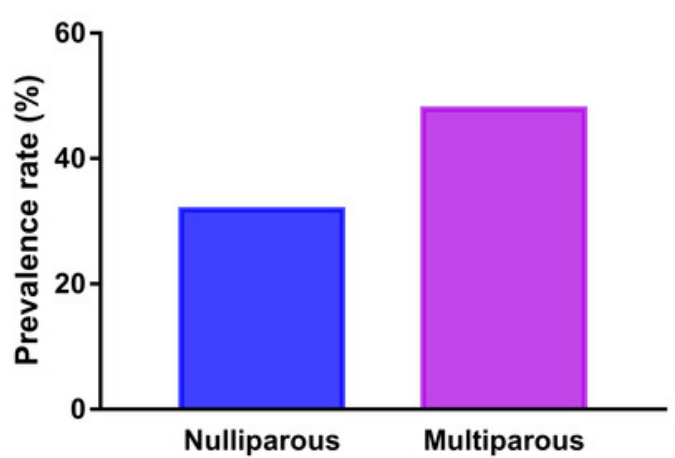

(A)

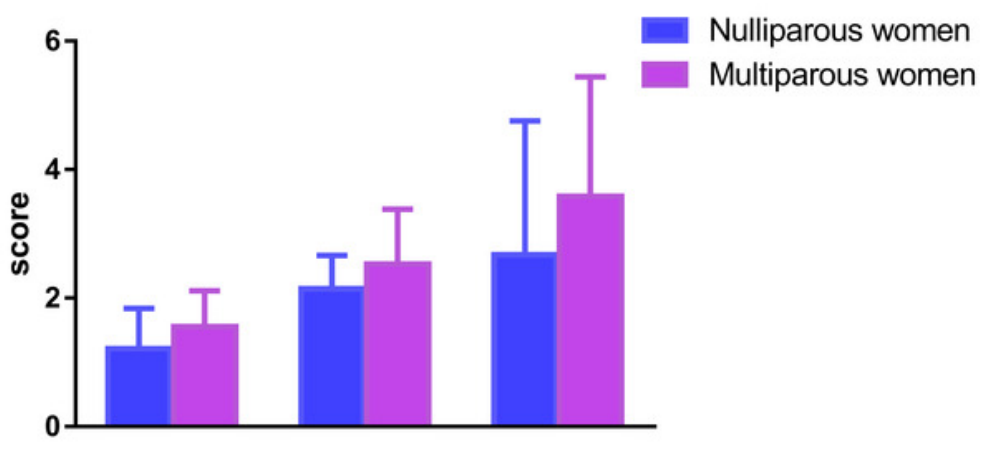

(B)

(D) 


\section{Table $\mathbf{1}$ (on next page)}

Comparison of demographic characteristics between nulliparous and multiparous women $(n=342)$

Notes.

${ }^{a} \mathrm{t}$

${ }^{\mathrm{b}} x^{2}$

*Significant difference between nulliparous and multiparous women.

BMI: body mass index. 
Table 1 Comparison of demographic characteristics between nulliparous and multiparous women $(n=342)$

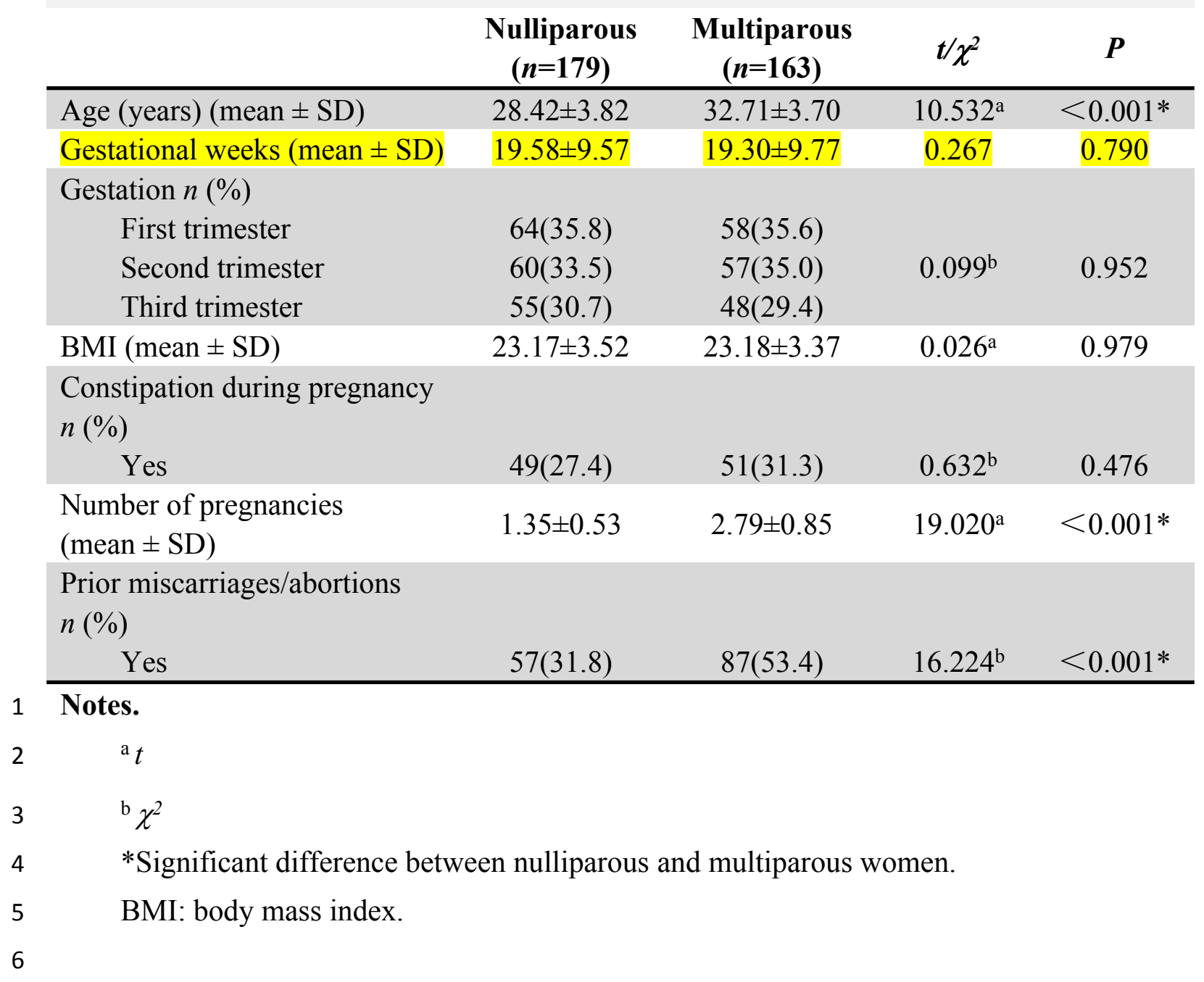




\section{Table 2 (on next page)}

Comparison of pelvic floor ultrasound parameters between pregnant women with and without UI $(n=342)$

Notes.

*Significant difference between pregnant women with and without UI.

UI: urinary incontinence; R: at rest; VM: maximal Valsalva maneuver; VM-R: the difference of VM and rest; BNVP: bladder neck vertical position; BND: bladder neck descent; HA: hiatal area. 


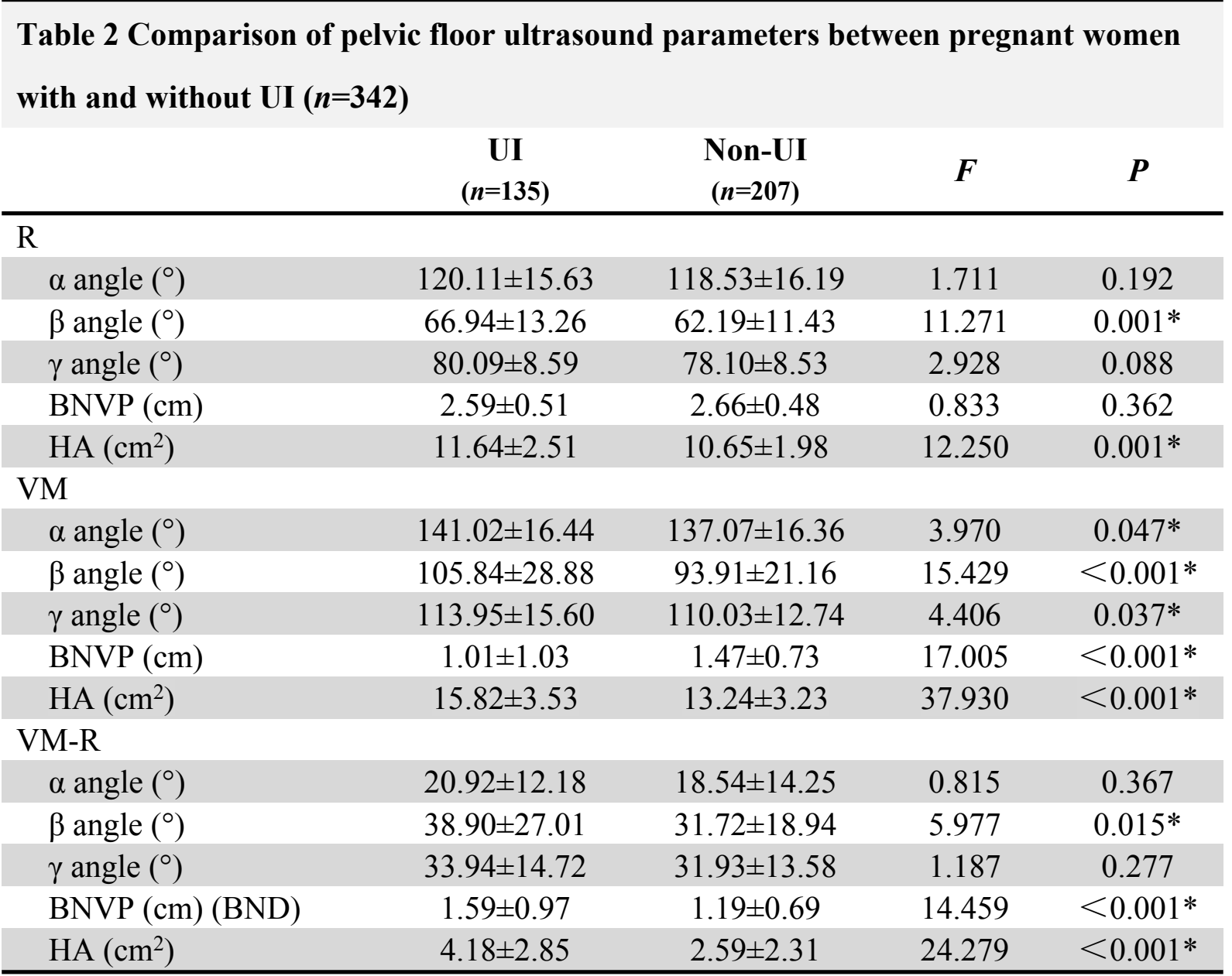

Notes.

$2 \quad *$ Significant difference between pregnant women with and without UI.

3 UI: urinary incontinence; R: at rest; VM: maximal Valsalva maneuver; VM-R: the

4 difference of VM and rest; BNVP: bladder neck vertical position; BND: bladder neck descent;

5 HA: hiatal area.

6 


\section{Table 3 (on next page)}

Comparison of pelvic floor ultrasound parameters between nulliparous and multiparous women $(n=342)$

Notes.

*Significant difference between nulliparous and multiparous women.

UI: urinary incontinence; R: at rest; VM: maximal Valsalva maneuver; VM-R: the difference of VM and rest; BNVP: bladder neck vertical position; BND: bladder neck descent; HA: hiatal area. 
Table 3 Comparison of pelvic floor ultrasound parameters between nulliparous and multiparous women $(n=342)$

\begin{tabular}{|c|c|c|c|c|}
\hline & $\begin{array}{c}\text { Nulliparous } \\
(n=179)\end{array}$ & $\begin{array}{c}\text { Multiparous } \\
(n=163)\end{array}$ & $F$ & $\boldsymbol{P}$ \\
\hline \multicolumn{5}{|l|}{$\mathrm{R}$} \\
\hline$\alpha$ angle $\left(^{\circ}\right)$ & $118.81 \pm 14.98$ & $119.54 \pm 17.03$ & 0.155 & 0.694 \\
\hline$\beta$ angle $\left(^{\circ}\right)$ & $62.99 \pm 13.37$ & $65.25 \pm 11.13$ & 2.904 & 0.089 \\
\hline$\gamma$ angle $\left(^{\circ}\right)$ & $78.44 \pm 9.62$ & $79.38 \pm 7.31$ & 1.112 & 0.292 \\
\hline BNVP $(\mathrm{cm})$ & $2.63 \pm 0.50$ & $2.65 \pm 0.48$ & 0.170 & 0.680 \\
\hline $\mathrm{HA}\left(\mathrm{cm}^{2}\right)$ & $10.99 \pm 2.25$ & $11.10 \pm 2.26$ & 0.251 & 0.616 \\
\hline \multicolumn{5}{|l|}{ VM } \\
\hline$\alpha$ angle $\left(^{\circ}\right)$ & $136.20 \pm 15.83$ & $141.31 \pm 16.82$ & 8.494 & $0.004 *$ \\
\hline$\beta$ angle $\left(^{\circ}\right)$ & $95.43 \pm 23.49$ & $102.12 \pm 26.48$ & 6.506 & $0.011 *$ \\
\hline$\gamma$ angle $\left(^{\circ}\right)$ & $109.25 \pm 12.62$ & $114.14 \pm 15.10$ & 11.074 & $0.001 *$ \\
\hline $\mathrm{BNVP}(\mathrm{cm})$ & $1.37 \pm 0.81$ & $1.19 \pm 0.96$ & 3.970 & $0.047 *$ \\
\hline $\mathrm{HA}\left(\mathrm{cm}^{2}\right)$ & $14.13 \pm 3.63$ & $14.40 \pm 3.51$ & 0.668 & 0.414 \\
\hline \multicolumn{5}{|l|}{ VM-R } \\
\hline$\alpha$ angle $\left(^{\circ}\right)$ & $17.39 \pm 12.28$ & $21.77 \pm 14.43$ & 10.008 & $0.002 *$ \\
\hline$\beta$ angle $\left(^{\circ}\right)$ & $32.44 \pm 20.42$ & $36.87 \pm 24.85$ & 3.478 & 0.063 \\
\hline$\gamma$ angle $\left(^{\circ}\right)$ & $30.82 \pm 12.32$ & $34.82 \pm 15.51$ & 7.144 & $0.008 *$ \\
\hline BNVP (BND) (cm) & $1.25 \pm 0.74$ & $1.46 \pm 0.91$ & 5.635 & $0.018^{*}$ \\
\hline $\mathrm{HA}\left(\mathrm{cm}^{2}\right)$ & $3.14 \pm 2.64$ & $3.30 \pm 2.67$ & 0.420 & 0.517 \\
\hline
\end{tabular}

1 Notes.

$2 \quad *$ Significant difference between nulliparous and multiparous women.

3 UI: urinary incontinence; R: at rest; VM: maximal Valsalva maneuver; VM-R: the

4 difference of VM and rest; BNVP: bladder neck vertical position; BND: bladder neck descent;

5 HA: hiatal area.

6 